\title{
Autosomal Dominant Microcephaly With Mental Retardation
}

\author{
E. Bawle and M. Horton \\ Department of Pediatrics, Wayne State University and Division of Genetic, Metabolic, and Developmental Disorders, \\ Children's Hospital of Michigan (E.B.) and Department of Pediatric Emergency, Henry Ford Hospital (M.H.), Detroit
}

A 3-year-old girl, her mother, and maternal uncle had microcephaly and mental retardation. Their facial appearance is characterized by deep-set eyes, short philtrums, and a beaked" nose. The mother and uncle live in an adult foster care facility because of mental retardation. The 3-year-old girl has a developmental quotient of 55. Mother has normal phenylalanine level and the child's chromosomes are normal. This appears to be a first report of a autosomal dominant form of microcephaly associated with mild to moderate mental retardation in contrast to absent or mild mental retardation described in earlier reports.

KEY WORDS: autosomal dominant, inheritance, microcephaly, mental deficiency

\section{INTRODUCTION}

Microcephaly defined as occipitofrontal head circumference (OFC) over 2.0 SD below the mean usually is associated with variable mental retardation. Recessively inherited microcephaly is associated with severe mental retardation [Kloepfer et al., 1964; Komai et al., 1955]. An autosomal dominant form of microcephaly with a nondistinctive phenotype was first reported by Haslam and Smith [1979]. Their 12 patients in 4 families had normal stature, most had a normal facial appearance, and, more importantly, had only borderline to mild mental retardation. Additional reports of dominantly inherited microcephaly with either normal or borderline intelligence have appeared [Burton, 1981; Ramirez et al., 1983; Rossi et al., 1987].

We report on a 3-year-old, microcephalic girl whose mother and maternal uncle also have microcephaly and mental retardation.

Received for publication September 26, 1988; revision received February 7, 1989.

Address reprint requests to Dr. Erawati Bawle, Genetic, Metabolic, and Developmental Disorders, Children's Hospital of Michigan, 3901 Beaubien, Detroit, MI 48201.

\section{CLINICAL REPORT}

The patient (E.B.) was born normally at term to a 28 year-old, primigravid mother. The pre- and postnatal periods were uneventful. Birth weight was $2,270 \mathrm{~g}$. Birth length and $\mathrm{OFC}$ were unavailable.

She was placed in foster care at age 5 days because of mother's mental retardation. The foster mother was concerned about delayed psychomotor development and slow weight gain despite a good appetite. We evaluated her at 5 months. She was a small child with a pinched nose and plagiocephaly. Her weight was $4.25 \mathrm{~kg}$ (<3rd centile), length $60.5 \mathrm{~cm}$ (10th centile), and OFC $36 \mathrm{~cm}(-5 \mathrm{SD})$.

Psychomotor development was delayed; i.e., she could not roll over or reach for objects. Diagnosis of microcephaly was made and nutritional deprivation was suspected because of postural flattening of the head and undernutrition. The biologic parents were unavailable at the time and the patient was lost to follow-up.

At 3 years, she was reevaluated at the request of her new foster mother. Examination showed severe microcephaly and growth failure. Her length was $85 \mathrm{~cm}(-2.9$ SD), weight $8.25 \mathrm{~kg}(-4.4 \mathrm{SD})$, and OFC $43.5 \mathrm{~cm}(-5.4$ $\mathrm{SD})$. She also had deep-set eyes, short philtrum, midface hypoplasia, pinched nose (Fig. 1), and single flexion crease on the 5th fingers. Ocular fundoscopy and other physical examination was normal.

Roentgenograms of long bones, hands, and wrists showed bone maturation of 18-24 months at a chronologic age of 35 months. Psychometric evaluation by Bailey Infant Developmental Test showed development at a 20-21 month range at a chronologic age of 36 months (moderate mental retardation). Peripheral lymphocyte chromosomes were normal $(46, \mathrm{XX})$. Physical measurements at 46 months showed steady linear growth $(5.5 \mathrm{~cm}$ in 11 months) and improved weight gain.

The new foster mother provided the following information about the biological parents. The mother and her brother lived in a foster home because of mental retardation. The mother's IQ had been estimated to be 72 and that of the uncle to be 52 . The maternal grandparents had died, but the grandmother was reported to be "slow." The biologic father's identity was uncertain.

We later examined E.B.'s mother and uncle. Mother was $165 \mathrm{~cm}$ tall and her OFC was $49 \mathrm{~cm}$ (-5 SD) (Fig. 2 ); the uncle was $173 \mathrm{~cm}$ tall, and his $O F C$ was $52 \mathrm{~cm}$ 

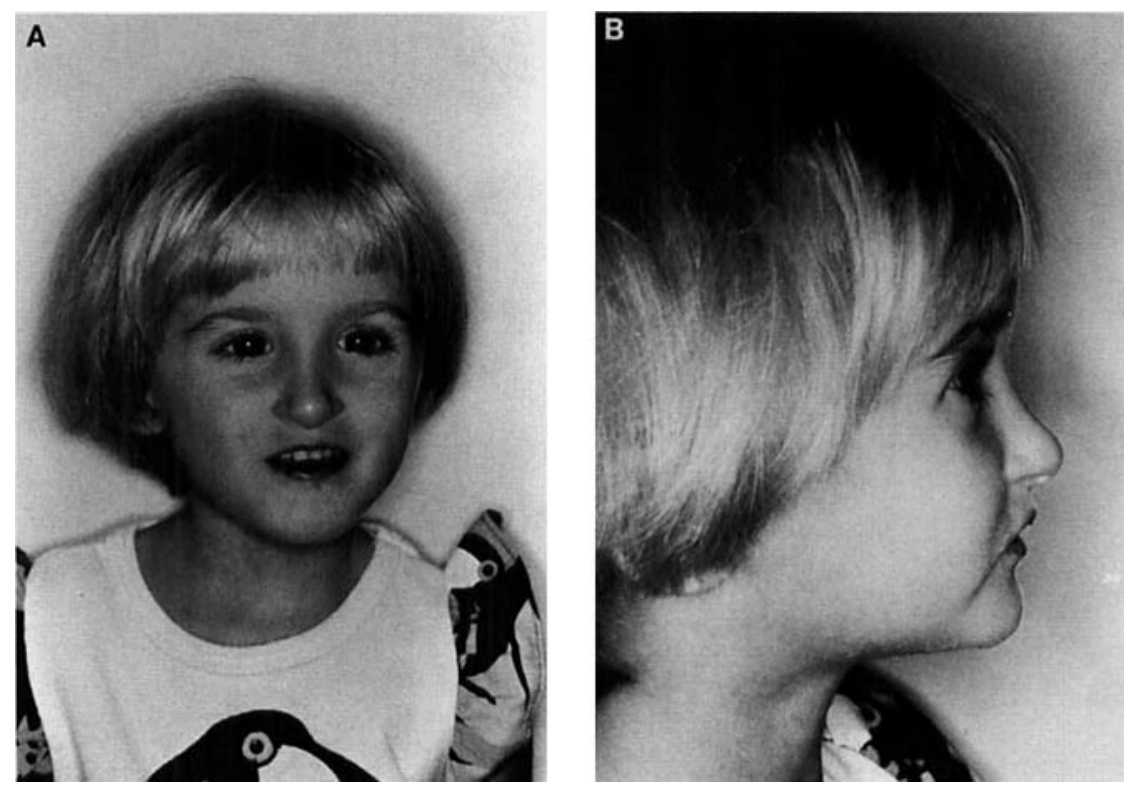

Fig. 1. a, b: Face of patient E.B.
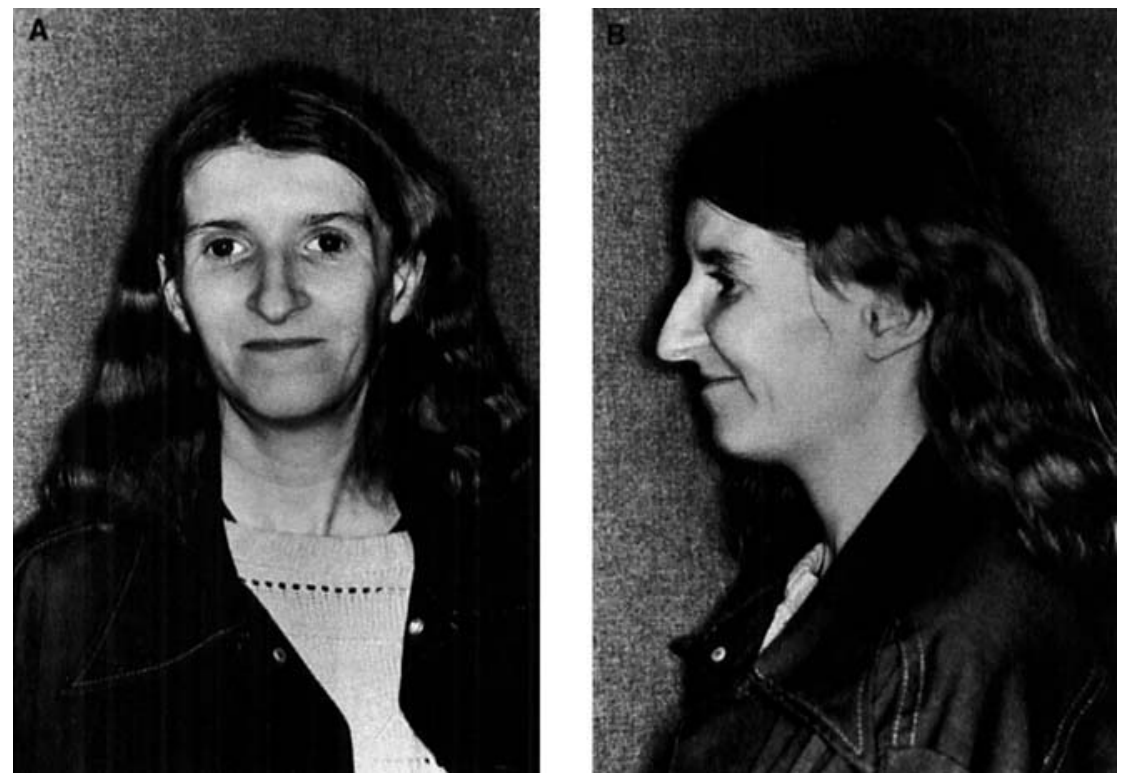

Fig. 2. a, b: Face of mother of E.B.

(-2.4 SD) (Fig. 3). The facial appearance was similar to that of E.B. with deep-set eyes, short philtrum, and beaked nose. The mother also had strabismus. Urine metabolic screening of E.B. and mother was normal. The mother's plasma aminoacid quantitation showed phenylalanine level of $4 \mu \mathrm{mol}$ per dl. On the Weschler Adult Intelligence Scale-Revised (WAIS-R) the mother obtained a score of 33 , equivalent to an IQ of 73 . This places her in the borderline mental retardation range. The uncle's IQ was 50 based on WAIS-R, placing him in the moderate mental retardation range. The mother and the uncle both showed severe impairment in visual motor coordination on the Bender-Gestalt Visual Motor Coordination Test.

\section{DISCUSSION}

This report documents the first instance of moderate mental retardation associated with probable autosomal dominant microcephaly. All 3 relatives are microcephalic. Two have moderate mental retardation and one has borderline retardation. EB's short stature may be due to 

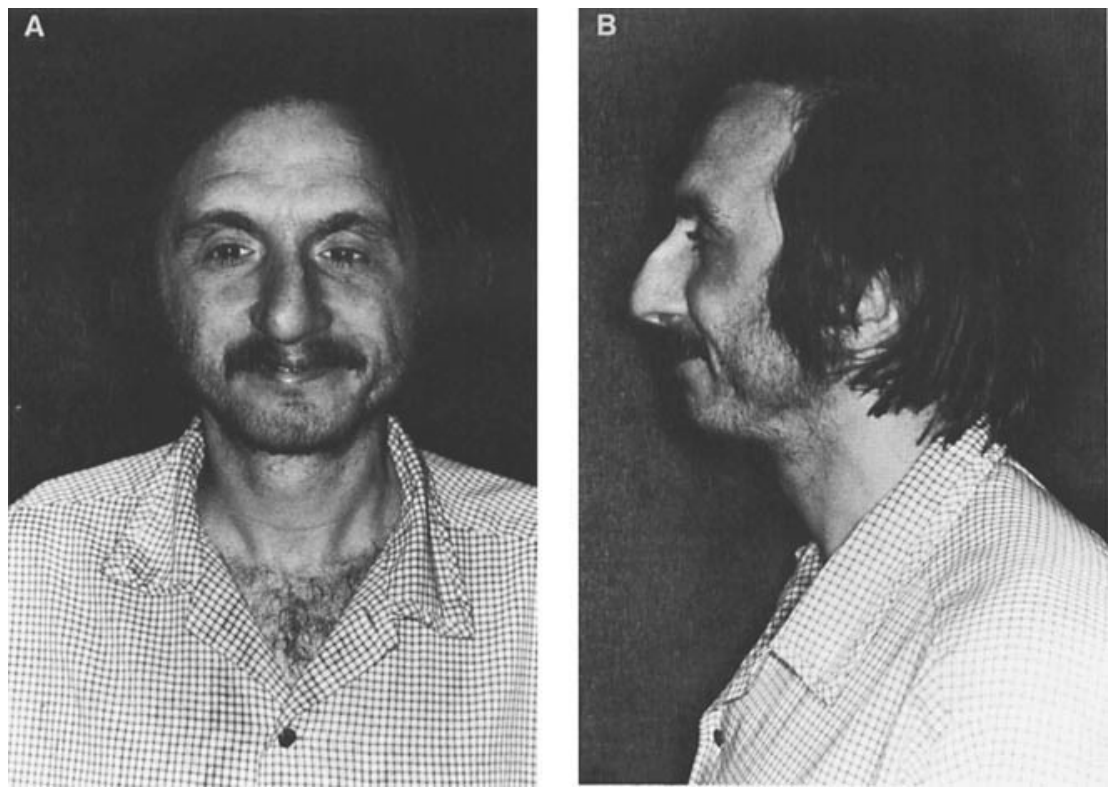

Fig. 3. a, b. Face of maternal uncle of E.B.

constitutional growth delay since the rate of growth appears normal and the mother and maternal uncle have a normal height. The facial appearance of all 3 is similar.

We think that autosomal dominant inheritance is likely. Our cases illustrate that autosomant dominant microcephaly is a heterogeneous entity. The intelligence may be normal or there may be mild to moderate retardation. Some cases of autosomal dominant microcephaly are associated with other anomalies like blepharophimosis [Bouwes et al., 1987], asymmetric crying face [Silengo et al., 1986], and lymphedema [Crowe and Dickerman, 1986; Leung, 1985].

We stress the importance of measuring parental OFC during the evaluation of a child with congenital microcephaly.

\section{REFERENCES}

Bouwes JN, Weaver DD, Ellis FD, Ward RE (1987): A syndrome of microcephaly, eye anomalies, short stature and mental deficiency. Am J Med Genet 26:825-831.
Burton BK (1981): Dominant inheritance of microcephaly with short stature. Clin Genet 20:25-27.

Crowe CA, Dickerman LH (1986): A genetic association between microcephaly and lymphedema. Am J Med Genet 24:131-135.

Haslam RHA, Smith DW (1979): Autosomal dominant microcephaly. J Pediatr 95:701-705.

Kloepfer HW, Platou RV, Hansche WJ (1964): Manifestations of a recessive gene for microcephaly in a population isolate. $J$ Genet Hum $13: 52-59$.

Komai T, Kishimoto K, Ozaki Y (1955): Genetic study of microcephaly based on Japanese material. Am J Hum Genet 7:51-65.

Leung AK (1985): Dominantly inherited syndrome of microcephaly and congenital lymphedema. Clin Genet 27:611-612.

Ramirez ML, Rivas F, Cantú JM (1983): Silent microcephaly: A distinct autosomal dominant trait. Clin Genet 23:281-286.

Rossi LN, Candini G, Scarlatti G, Rossi G, Prina E, Alberti S (1987): Autosomal dominant microcephaly without mental retardation. Am J Dis Child 141:655-659.

Silengo MC, Bell GL, Biagioli M, Guala A, Bianco R, Strandoni P, De Sario PN, Franceschini P (1986): Asymmetric crying facies with microcephaly and mental retardation. An autosomal dominant syndrome with variable expressivity. Clin Genet 30:481-484. 